\title{
TIERRA POR VOTOS. ADJUDICACIÓN DE BALDÍOS DURANTE LA REPÚBLICA LIBERAL, 1930-1946*
}

\author{
Fabio Sánchez Torres \\ Pilar Torres Alvaradob \\ Marta Juanita Villaveces Niñoc
}

"DOI: https://doi.org/10.18601/01245996.v22n43.11 Este artículo es resultado de las discusiones de un trabajo anterior, The paradox of land reform. Agradecemos a Jorge Caputo por su asistencia en la investigación, así como los comentarios de Jorge Gallego, Stanislao Maldonado, Francesco Bogliacino y de los asistentes al Forum of Economist International 2017, al MPSA 2016 y al Seminario de Investigación de la Escuela de Economía de la Universidad Nacional de Colombia. Recepción: 25-10-2018, modificación final: 28-03-2020, aceptación: 06-05-2020. Sugerencia de citación: Sánchez, T. F., Torres, A. P. y Villaveces, N. M. (2020). Tierra por votos. Adjudicación de baldíos en Colombia durante la República Liberal, 1930-1946. Revista de Economía Institucional, 22(43), 249-275.

${ }^{a} \mathrm{PhD}$ en Economía. Profesor titular, Facultad de Economía, Universidad de los Andes, Bogotá, Colombia, [fasanche@uniandes.edu.co], [https://orcid. org/0000-0003-2172-5572].

b Maestría en Economía. Profesora temporal, Facultad de Economía, Universidad del Rosario, Bogotá, Colombia, [pilar.torres@urosario.edu.co], [https:// orcid.org/0000-0002-0649-0755].

c PhD en Estudios Políticos. Profesora asociada, Escuela de Economía, Universidad Nacional de Colombia, Bogotá, Colombia, [mjvillavecesn@unal. edu.co], [https://orcid.org/0000-0001-6185-4470]. 
Tierra por votos. Adjudicación de baldíos durante la República Liberal, 1930-1946

Resumen. ¿Es posible que el gobierno de turno reparta tierras baldías para premiar a los electores y aumentar el apoyo electoral? Los gobiernos utilizan mecanismos distributivos para obtener réditos electorales. Este trabajo analiza la relación entre la adjudicación de baldíos y las elecciones de 1930 a 1946 -cuando el partido liberal se consolidó como fuerza electoral- mediante un modelo de mínimos cuadrados ordinarios que incluye más de 600 municipios. Los resultados muestran que la adjudicación de baldíos favoreció a municipios liberales, aunque no está asociada con mayorías electorales del partido liberal en 1946.

Palabras clave: distribución, elecciones, adjudicación de baldíos, partido liberal; JEL: D33, Q15, D72

\section{Land forvotes. Land reform in Colombia during the República Liberal, 1930-1946}

Abstract. Is it possible that public land allocation by the government might be a mechanism to reward voters and, eventually, increase electoral support? The literature suggests that governments use distributive mechanisms to obtain electoral revenues. To analyze this, we assessed the relation between land allocation and elections between 1930 and 1946, when the Liberal Party was consolidated as the main electoral force. We implemented an Ordinary Least Squares model for more than 600 municipalities and the results show that public land allocation did favor the liberal municipalities, although it is not associated with the electoral results of the Liberal Party in the 1946 elections.

Keywords: Distribution, elections, public land distribution, liberal party; JEL: D33, Q15, D72

\section{Terra por votos. Atribuição de lotes vagos durante a República Liberal, 1930-1946}

Resumo. É possível que o governo no poder distribua terras vazias para recompensar os eleitores e aumentar o apoio eleitoral? Os governos usam mecanismos distributivos para obter retornos eleitorais. Este trabalho analisa a relação entre a alocação de lotes vagos e as eleições de 1930 a 1946 - quando o partido liberal foi consolidado como força eleitoral - por meio de um modelo ordinário de mínimos quadrados que inclui mais de 600 municípios. Os resultados mostram que a alocação de lotes vagos favoreceu os municípios liberais, embora não tenha sido associada às maiorias eleitorais do partido liberal em 1946.

Palavras-chave: distribuição, eleições, alocação de lotes vagos, partido liberal; JEL: D33, Q15, D72 
Es posible que el gobierno de turno reparta tierras baldías para premiar a los electores y aumentar el apoyo electoral? Si bien algunos autores señalan que los políticos adoptan estrategias para atraer votantes según su identificación ideológica, étnica o social (Downs, 1957; Formisano, 1971; Cox y Mccubbins, 1983), otros autores afirman que hay votantes indecisos, que les exigen incentivos específicos para tomar su decisión electoral (Banfield y Wilson, 1963 y Scott, 1972). Entre ellos, los gobernantes usan políticas distributivas para crear incentivos electorales que no siempre se focalizan en los electores seguros y fieles, sino para atraer votantes indecisos (Stokes, 2005; Nichter, 2008). En ese debate se sostiene que la distribución de bienes, por los gobiernos de turno y los políticos en campaña, puede buscar una lealtad duradera o premiar esporádicamente a los electores (Cox y McCubbins, 1986; Dixit y Londregan, 1996; Lindbeck y Weibull, 1993, y Nazareno, Stokes y Brusco, 2006). Es decir, no solo se trata de beneficiar a los electores potenciales en épocas de campaña sino que puede ser una práctica clientelista. Desde esta perspectiva, es válido asociar la política distributiva con los intereses electorales en un entorno de votantes cambiantes que se pueden captar con incentivos.

Nichter (2008) y Wang y Kurzman (2007) señalan que los políticos en campaña entregan bienes en un solo momento -cargos públicos, dinero, alimentos o material de construcción- en época electoral. Para Nichter (2008), la entrega de bienes el día de las elecciones busca activar votantes leales pero pasivos. Para Wang y Kurzman (2007), esta estrategia no siempre persiste en el tiempo. Cada elección requiere una nueva entrega de bienes para recibir apoyo electoral.

Albertus (2015) sostiene que la política distributiva y los bienes entregados no son homogéneos y que no es lo mismo entregar un bien que se debe devolver si no se ha dado apoyo electoral (como un cargo laboral), que un bien como la tierra, difícil de quitárselo al receptor, que puede generar apoyo en varias elecciones. Por ello, la estrategia distributiva lleva a que los políticos entreguen bienes distintos a los votantes indecisos y a los fieles, y su entrega no siempre coincide con el periodo electoral. En este artículo se argumenta que la tierra se puede usar como política distributiva, para captar votantes indecisos cuando su apoyo puede modificar los resultados electorales. Como argumenta Albertus, el votante indeciso no solo cambia su decisión electoral cuando recibe un pago único, sino que puede dar un apoyo más duradero cuando recibe un bien más valorado, como la tierra. 
La adjudicación de baldíos ${ }^{1}$ entre 1930 y 1946 puede ejemplificar la relación entre distribución de bienes públicos y fines electorales. El partido liberal implementó una serie de reformas que buscaban modernizar el país, pero que también pudieron ser utilizadas con fines electorales $^{2}$. Una de ellas fue la Ley de Tierras (Ley 200 de 1936), que creó mecanismos para reconocer y adjudicar tierras baldías a campesinos, colonos y grandes propietarios. El partido liberal no ganó las elecciones presidenciales durante más de cincuenta años. Pero en 1930 logró la presidencia con el 44\% de la votación, y aunque en 1946 perdió las elecciones consiguió el $60 \%$ de los votos ${ }^{3}$, y se consolidó como fuerza política. En este contexto se analiza si la adjudicación de baldíos incidió en los resultados electorales posteriores.

Una mirada a la adjudicación de baldíos después de las elecciones de 1930 muestra que los municipios que votaron por el partido liberal tuvieron más adjudicaciones que los que votaron por el partido conservador. En promedio, se adjudicaron más predios y un mayor número de hectáreas donde ganó el partido liberal, como muestra la gráfica 1 . Esta tendencia sugiere que se pudo premiar a los seguidores del partido liberal, en vez de adjudicarlos conforme a los lineamientos técnicos definidos en la ley. De haber seguido esos lineamientos habría mayor semejanza en todos los municipios, sin que importara su filiación política ni su votación en la elección presidencial de 1930.

La correlación entre el voto liberal en 1930 y la adjudicación de baldíos entre 1930 y 1946 indica una asociación positiva y significativa con el número y el área de los predios adjudicados. Puesto que donde ganó el partido liberal se adjudicaron más predios y más área (cuadro

1 Conforme a la legislación colombiana, un baldío es un bien inmueble de propiedad de la Nación ubicado en zonas rurales que, como regla general, se debe adjudicar quienes lo ocupen y cumplan los requisitos legales. El proceso de adjudicación varía según la ley vigente. Desde 1936, con la Ley 200, se presume que los fundos poseídos por particulares no son baldíos sino de propiedad privada, entendiendo que esa posesión consiste en la explotación económica del suelo por medio de hechos positivos propios de dueño. A diferencia de otros países latinoamericanos, en Colombia la política de tierras se ha basado en la abundancia de tierras, cuya vasta extensión no solo hizo posible la ampliación de la frontera agrícola sino que facilitó el acceso la tierra a través de la política pública, sin necesidad de redistribuir tierras improductivas en manos particulares.

2 Entre ellas cabe mencionar las reformas tributaria, laboral y educativa, además de la ley de tierras. Robinson (2007) señala que la política colombiana es de carácter clientelista y exige distribuir bienes para lograr objetivos electorales.

${ }^{3}$ E1 aumento del apoyo electoral al partido liberal no lo llevó a la presidencia porque sus votos se dividieron entre sus dos candidatos, y el candidato conservador triunfó con menos del 35\% de la votación. 
1), el partido liberal parece haber favorecido a los municipios donde triunfó en la elección presidencial de 1930. Cabe entonces preguntar si hubo una estrategia particular en la adjudicación de baldíos y si afectó la votación en las elecciones de 1946.

Gráfica 1

Predios y superficie promedio adjudicados entre 1930-1946

A nivel municipal, según partido ganador en 1930
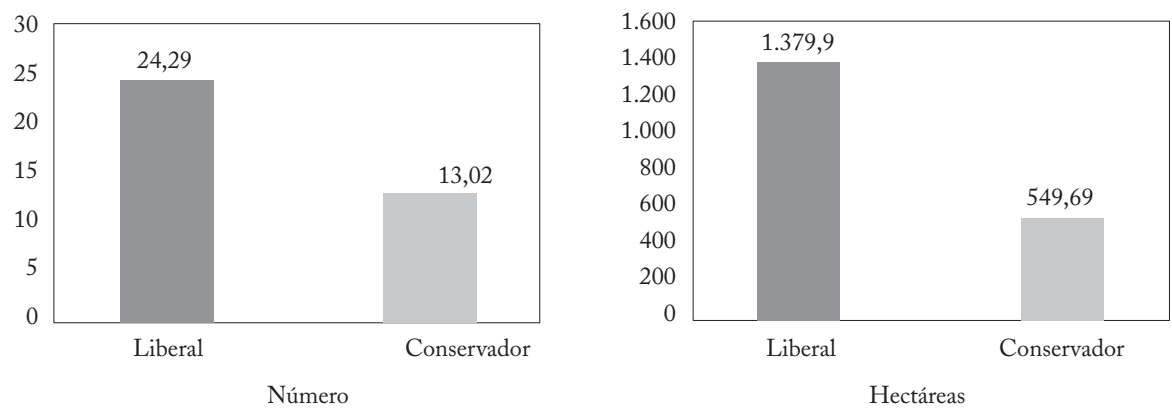

Fuente: Información electoral: Ministerio del Interior. Adjudicación de baldíos, Sider, cálculos propios.

Cuadro 1

Correlación entre victoria del partido liberal en 1930

y adjudicación de baldíos entre 1930 y 1946

\begin{tabular}{lcc}
\hline Variables & $\begin{array}{c}(1) \\
\text { Adjudicaciones } \\
\text { Número }\end{array}$ & $\begin{array}{c}(2) \\
\text { Adjudicaciones } \\
\text { Hectáreas }\end{array}$ \\
\hline D.liberal & $11,21^{* *}$ & $789,5^{* * *}$ \\
& $(-5,664)$ & $(-303,2)$ \\
Constante & $10,39^{* * *}$ & $472,3^{* * *}$ \\
& $(-3,732)$ & $(-199,7)$ \\
\hline Observaciones & 645 & 645 \\
$\mathrm{R}^{2}$ & 0,006 & 0,010 \\
\hline
\end{tabular}

Errores estándar entre paréntesis; * $\mathrm{p}<0,1 ;{ }^{* *} \mathrm{p}<0,05 ;{ }^{* * *} \mathrm{p}<0,01$.

Fuente: elaboración propia.

La pregunta sobre la política de tierras y la adjudicación de baldíos para lograr apoyo electoral cobra fuerza a la luz de los hechos históricos de 1930 a 1946. Como señala Vanegas "E1 liberalismo de estos años no solo se preocupó por construir una mayoría electoral sino que también consagró esfuerzos importantes a transformar los vínculos sociales y a tratar de hacer arraigar nuevos principios y prácticas políticas" (2015, p. 24). Esto sugiere que los medios para lograr un apoyo mayoritario no solo incluían una estrategia de corto plazo sino una estrategia para modificar los vínculos con los partidos políticos y lograr un apoyo más duradero. 
Para explorar la relación entre el comportamiento del partido liberal y la adjudicación de baldíos se consideran dos escenarios: el de la adjudicación de baldíos como resultado de la votación de 1930 y el nexo potencial entre la adjudicación de baldíos en el periodo 19301946 y los resultados electorales de 1946. Este último da luz sobre la posibilidad de que la política de adjudicación de baldíos favoreciera la consolidación del partido liberal como fuerza política en 1946.

Ambos escenarios se abordan usando los datos disponibles. En el primer caso, se plantea un modelo de mínimos cuadrados ordinarios (MCO), con los resultados de la elección presidencial de 1930, que compara la adjudicación de baldíos en los municipios donde el partido liberal ganó por un margen muy estrecho y en los que perdió por muy poco, para determinar si los municipios con preferencias débiles o indecisas recibieron más adjudicaciones en 1930-1946. En el segundo caso, se estimó otro modelo MCO para determinar si el esfuerzo para adjudicar baldíos previamente se tradujo en votos en 1946.

La relación entre la política de adjudicación de baldíos y los intereses electorales no ha sido abordada en Colombia desde una perspectiva empírica; este trabajo es un aporte a la literatura sobre las políticas distributivas y los efectos electorales entre 1930 y 1946. Esta es solo una aproximación que lleva a plantear nuevos interrogantes que no ha considerado la literatura, y no pretende ser taxativa.

En la primera sección se revisa la literatura y en la segunda el contexto político de la Ley de Tierras de la República Liberal. En la tercera, que describe la estrategia empírica, se explican los métodos utilizados y en la cuarta se muestran los resultados. Se concluye que el partido liberal tuvo un comportamiento oportunista en la ejecución de la política de tierras y que la adjudicación de baldíos estuvo relacionada con los resultados electorales de 1946.

\section{POLÍTICA DISTRIBUTIVA Y PROVISIÓN DE BIENES}

La literatura sobre la compra de votantes examina las condiciones que, en un ambiente competitivo, llevan a que los partidos ofrezcan incentivos materiales a cambio de votos. El debate se centra en dos aspectos: si se beneficia al electorado leal y del núcleo del partido o se busca incidir en los votantes indecisos. Esto último difiere de la lealtad de largo plazo, que exige un vínculo más estrecho con los votantes; el cual, a través del clientelismo, la lealtad o la identidad, permite utilizar las políticas públicas con fines electorales (Franzese, 2002). 
Existen distintas estrategias: para algunos autores, el grupo favorecido con la "compra de votos" es el de los votantes que no tienen fuertes preferencias políticas, es decir, que pueden cambiar fácilmente su voto (Weibull 1987, Dixit y Londregan 1996, Wright 1974 y Johansen 2002). Otros autores sostienen que los principales beneficiados son los votantes más leales (Cox y McCubbins, 1986), Dasgupta et al. (2001)).

Dixit y Londregan y Lindebeck y Weibul (1987) usan el concepto de redistribución táctica, el cual indica que la política redistributiva se dirige a los grupos del centro del espectro político, que pueden modificar rápidamente cambiar su decisión de voto (swing voters). Stokes (2005) afirma que la focalización en los votantes indecisos puede generar más réditos electorales que centrarse en los leales, sobre cuyo voto hay certeza y no es necesario gastar recursos.

Por otra parte, Dixit (1996), Dixit, Grossman y Helpman (1997) y Grossman y Helpman (1992) sostienen que la distribución busca favorecer grupos de interés específicos que hicieron contribuciones al gobierno a cambio de favores políticos. Otros autores, como Nazareno, Stokes y Brusco (2006) y Albertus (2015) argumentan que los partidos políticos tienden a combinar todo tipo de estrategias - pues centrarse en un solo grupo es muy riesgoso- $y$ así benefician a votantes leales, indecisos e incluso opositores.

Para Albertus, la tierra tiene características que garantizan el apoyo de los votantes indecisos: su oferta finita y su capacidad para generar pagos futuros a los beneficiarios. Los retornos de la entrega de tierras no solo son de corto plazo, sino que reportan réditos de largo plazo al partido que las distribuyó, con un costo decreciente. Con la entrega de bienes durables como la tierra, la adhesión de los votantes indecisos puede durar más de una elección, no solo porque recuerdan al candidato asociado a la tierra que poseen sino por agradecimiento, cuando obtienen rendimientos de la tierra (ibíd.).

También se han encontrado vínculos entre entrega de tierras y resultados electorales en México, Venezuela e India. En el caso de reforma agraria en México, Albertus et al. (2016) muestran que el gobierno tuvo un comportamiento oportunista, y otorgó más hectáreas donde menos apoyo recibió. Y Fergusson, Larreguy y Riaño (2015) encuentran que el gobierno no ejecutó la política de manera efectiva en los lugares donde había mayor competencia política. En Venezuela, Albertus (2015) encontró que los partidos se focalizan en los votantes indecisos y en sus votantes leales. La tierra se distribuyó en zonas de alta competencia política, mientras que la inversión rural 
se focalizó en los lugares donde los partidos tenían un electorado fiel, en ambos casos con favorables resultados electorales. En el caso de India, Bardhan y Mookherjee (2010) evalúan los determinantes políticos de la reforma agraria en Bengala Occidental y encuentran un comportamiento oportunista del partido de izquierda (abanderado de la política de tierras), que aprovechó su ventaja electoral para crear esa necesidad en el electorado y seguir en el poder. El resultado fue la ineficiente ejecución de la reforma agraria.

Los trabajos mencionados examinan los efectos del oportunismo partidista en la ejecución de la política de tierras, un tema de interés para este trabajo que busca entender la adjudicación de baldíos como causa y consecuencia de la dinámica política en Colombia durante 1930 y 1946, sin considerar los efectos económicos que pueden ser tema de trabajos futuras. El análisis de Albertus sobre de Venezuela es relevante para entender el caso colombiano, pues la entrega de tierras pudo tener efectos en elecciones posteriores, 16 años después del triunfo liberal, al captar votantes indecisos o por primera vez. Por su parte, el trabajo de Albertus et al. (2016), sobre México detecta la estrategia de entregar gran cantidad de tierras en lugares de bajo apoyo político. Es posible que, entre 1930 y 1946, en Colombia se entregaran tierras para obtener resultados electorales posteriores a la y cantidades diferentes de tierras para lograr apoyo político.

Existe una amplia literatura sobre la política de tierras de la República Liberal. No obstante, ninguno de los trabajos presenta ejercicios empíricos que validen las hipótesis de sus autores, como se hace aquí. En su mayoría, esos trabajos sostienen que la Ley 200 de 1936 fue inocua para resolver los graves de la tenencia de la tierra, e incluso que fue un rotundo fracaso por su ineficacia para enfrentar la desigual distribución de la tierra. Aquí cabe mencionar los trabajos de Palacios (2011), Berry (2002), Machado (2009) y LeGrand (1988).

Palacios argumenta que dicha el fracaso porque excluyó otros graves aspectos de la cuestión agraria, como la desigual distribución de la tierra, la baja productividad y la relación entre el sector agrícola y los demás sectores. Berry sostiene que si bien la ley de tierras se concibió para favorecer a los colonizadores, no frenó la acumulación de tierras públicas y no apaciguó las tensiones entre colonos y grandes empresarios. Además, Berry y Machado argumentan que la Ley 200 fortaleció a los grandes propietarios agrícolas, porque no modificó la concentración del poder ni emprendió transformaciones que promovieran al ascenso social. En palabras de LeGrand: "al reforzar la posición económica y política de las élites terratenientes, la Ley 200 de 
1936 creó el escenario para el desarrollo futuro del campo colombiano con base en grandes propiedades privadas" (1988, p. 206).

Por su parte, Uprimny (1989) asocia el letargo de la política de tierras a las prácticas clientelistas basadas en las relaciones de dependencia entre terratenientes y campesinos, propias de las estructuras agrarias donde predomina el latifundio. Esta dependencia crea vínculos electorales entre campesinos y dueños de la tierra.

Puesto que la política de tierras tenía un componente distributivo, pues buscaba que los campesinos desterrados tuvieran parcelas para mejorar su calidad de vida y su actividad productiva, se esperaría que hubiese sido guiada por criterios de eficiencia. No obstante, en la práctica el acceso y el control de la tierra han estado asociados a intereses electorales y de control político y social (Fajardo, 2014).

\section{PARTIDOS POLÍTICOS Y POLÍTICA DE TIERRAS, 1930-1946}

\section{Política de TIERRAS}

La adjudicación de baldíos en Colombia se puede rastrear desde la Independencia hasta hoy días. Ha sido una política continua, con cambios en su ejecución y en las reglas de acceso. Desde la Independencia, y durante gran parte del siglo XIX, la adjudicación de baldíos sirvió para saldar las deudas de la naciente República con los soldados y prestamistas que ayudaron a ganar las guerras; y funcionó como bono de deuda para financiar la construcción del Estado (Villaveces y Sánchez, 2014). A finales del siglo XIX, la adjudicación de baldíos amplió la frontera agrícola (Machado, 2009).

En el siglo XX, la adjudicación de baldíos ha girado en torno a tres grandes objetivos: fomentar la productividad rural, corregir las inconsistencias en la tenencia de la tierra y resolver conflictos rurales. En el siglo XX se promulgaron tres leyes de tierras, en 1936, 1961 y 1994'; se adjudicaron 23 millones de hectáreas, un 20\% del territorio del país y un 50\% de la tierra cultivable (Faguet, Sánchez y Villaveces, 2015). La adjudicación de baldíos ha consistido en entregar tierras a campesinos en pequeña propiedad y a latifundistas en grandes propiedades, que cumplen los requisitos de uso, posesión y permanencia previa. Más que una reforma agraria redistributiva, ha sido una distribución de tierras del Estado a propietarios privados.

${ }^{4}$ En el siglo XX se promulgaron tres leyes orgánicas de tierras o de reforma agraria (denominadas así por el legislador primario): la Ley 200 de 1936, la Ley 135 de 1961 y la Ley 160 de 1994 que aún está vigente. 
La política de tierras de la década de 1930, emblemática de las reformas liberales, buscaba legitimar el acceso previo a la tierra y resolver los conflictos por títulos y límites que venían desde comienzos del siglo XX. Como señala Fajardo (2014), la adjudicación de baldíos en grandes propiedades y la expansión de las haciendas en zonas baldías generaron una presión sobre las tierras ocupadas por pequeños propietarios como resultado de la colonización. Esta presión o "cerco" de las grandes haciendas llevó a los campesinos a buscar tierra fuera del cerco y desató procesos de colonización que ampliaron la frontera agraria; en medio del conflicto por la tierra y el uso del poder de facto en favor de las tierras de los hacendados.

La Ley 200 de 1936 atacó varios problemas del campo, como el de la violencia y el de las tierras inexplotadas, e intentó "transformar el latifundio ocioso en empresa capitalista moderna", como señaló Darío Echandía, ministro de Gobierno en ese entonces (Machado, 2009; Arango, 2014).

La política de adjudicación de baldíos ha intentado dar acceso a la tierra a campesinos desterrados y resolver disputas sobre la tenencia de la tierra, agudizadas por los conflictos rurales. Además, ha sido una estrategia de los gobiernos para construir obras públicas y atender necesidades de los municipios con migración y crecimiento poblacional. Esto explica por qué ha sido una continua, no siempre con fines redistributivos. A comienzos del siglo XX, el gobierno conservador usó la adjudicación de baldíos para construir obras públicas y para los entes territoriales, durante la consolidación de las principales ciudades (Machado, 2009).

Por otra parte, la política agraria ha sido afectada por intereses partidistas. El partido conservador ha sido contrario a la distribución y redistribución de la tierra, y favorable a la defensa de los grandes latifundistas de origen colonial o republicano, con políticas que resguardan la propiedad de la élite rural sin mayores costos tributarios (Kalmanovitz, 2006). Por su parte, el partido liberal ha estado a favor de desmontar las trabas a la libre movilidad de la tierra, incluidos los privilegios heredados de la Colonia, y de mejorar la productividad de la tierra (Palacios, 2011; Machado, 2009). Las tres leyes de reforma y uso de la tierra del siglo XX (Ley 200 de 1936, Ley 135 de 1961 y Ley 160 de 1994) fueron obra del partido liberal. Estas posiciones partidistas se reflejan en el patrón de adjudicación de baldíos, durante la Hegemonía Conservadora (1905-1930) y durante la República Liberal (1930-1946), como muestran las gráficas 1 y 2. 
Gráfica 2

Tendencia de la adjudicación de baldíos, 1901-1946

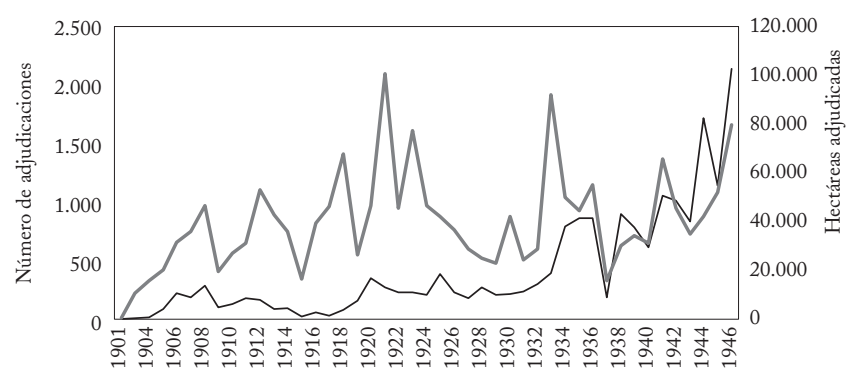

Fuente: Sider-Incoder, elaboración propia.

En el periodo de análisis, la Ley 200 de 1936 buscaba favorecer a quienes colonizaron nuevas tierras desde finales de siglo XIX. Además, esa ley definió por primera vez la función social de la propiedad, intentó mejorar el uso de la tierra y su productividad, permitió parcelar las grandes haciendas y contempló la posibilidad de expropiar tierras inexplotadas (Sánchez y Villaveces, 2015; Machado, 2009). Esta posibilidad irritó a las élites terratenientes, que presionaron para dar paso a la Ley 100 de 1944, que neutralizaría los efectos de la ley de tierras, extendiendo el plazo de expropiación sin remuneración diez años más, y estableciendo que los contratos de arrendamiento serían se utilidad pública, donde primaría la "coparticipación en la explotación de las tierras” (Franco y de los Ríos, 2011, p. 102).

Los dos pilares del gobierno de Alfonso López Pumarejo fueron la reforma constitucional de 1935 y la ley de tierras, basadas en argumentos de progreso y modernización del Estado, y en la idea de que la población las apoyaría si se lograba mayor estabilidad social y política para que su participación en la actividad económica contribuyera al desarrollo. También traslucían un proyecto democrático que ampliaba o reconocía derechos. Así, la Ley 200 de 1936 era un proyecto político de cambio que tendría efectos en la configuración política, los derechos individuales, el lugar del Estado y la función de la tierra. Aunque las reformas impulsadas en ese periodo, aunque tuvieron fuertes detractores y fueron polémicas, dieron un viraje al desarrollo nacional y un fuerte respaldo popular al partido liberal (Martínez, 2013).

Durante los 16 años del República Liberal, la política de tierras fue un bastión del gobierno, que introdujo grandes cambios a las leyes que antes definían el acceso a la tierra. Los liberales prometieron revisar y mejorar el acceso a la tierra y promulgaron la Ley 200 de 1936, 
cuyos ejes eran la función social de la propiedad, el reconocimiento de los derechos de los colonos y los mecanismos para acceder a la propiedad los baldíos.

Esta Ley fue motivada por el conflicto agrario y para resolver disputas entre dueños y colonos. En la práctica, el gobierno liberal adjudicó unas 800 mil ha en 14.043 predios, un promedio de 54 ha, mientras que los gobiernos conservadores anteriores adjudicaron algo más de un millón de ha en 4.478 predios, un promedio de 231,88 ha. Es decir, durante la República Liberal se adjudicaron más predios y más pequeños que durante la Hegemonía Conservadora.

\section{Gráfica 3}

Baldíos adjudicados por la Hegemonía Conservadora y la República Liberal (Número y área, porcentaje por tamaño de los predios)
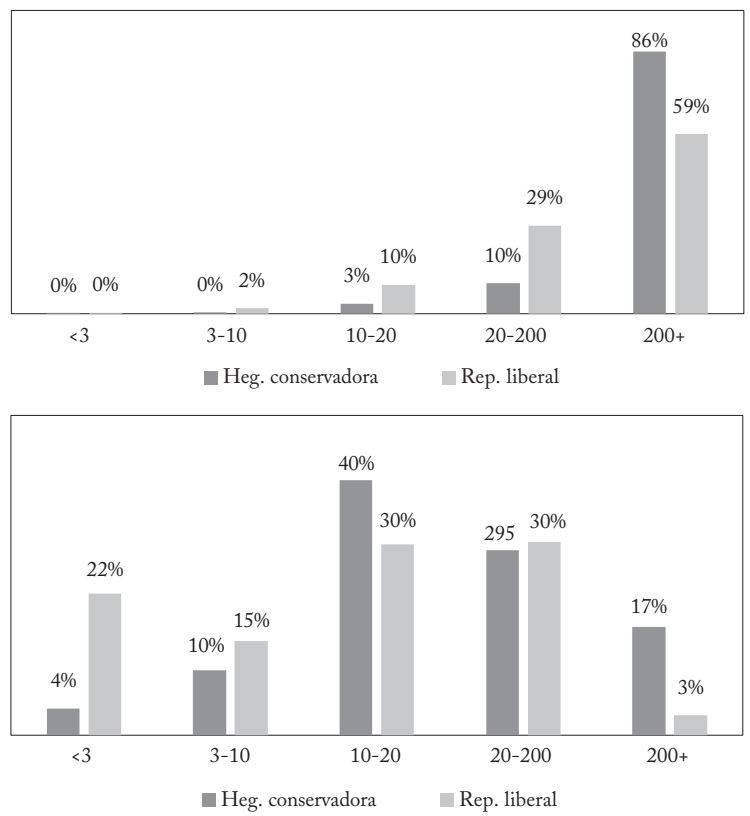

Fuente: Sider-Incoder, elaboración propia.

En términos más específicos, durante la República Liberal, la adjudicación de microfundios aumentó del $4 \%$ al 22\% mientras que la adjudicación de latifundios se redujo del $17 \%$ al $3 \%$, con respecto al número total de predios ${ }^{5}$. El esfuerzo por adjudicar predios de menor

${ }^{5}$ Los microfundios tienen una superficie de menor de 3 ha; los minifundios, de 3 a 10 ha; las pequeñas propiedades, de 10 a 20 has y las medianas, de 20 a 200 ha. Los latifundios son predios de más de doscientas ha. 
tamaño es consistente con el interés de reconocer las tierras a los colonos y con la intención de ampliar el acceso a la tierra. Además, el tamaño de los predios de mayor adjudicación fue de 10 a 200 ha, es decir, a pequeños y medianos propietarios (gráfica 3).

Después de la década de 1930 la adjudicación de baldíos dio un giro, porque con la reforma de 1936, el número de adjudicaciones empezó a crecer en forma notoria, manteniendo un nivel similar de hectáreas (gráfica 4), aunque con un comportamiento cíclico cercano al de las elecciones presidenciales. En el año anterior a las elecciones $(1930,1934,1938,1942$ y 1946) tendían a aumentar las adjudicaciones, en número y área, después disminuían y aumentaban de nuevo en el año anterior a la siguiente elección. Este hecho estilizado muestra una posible relación entre la adjudicación de baldíos y las elecciones presidenciales.

Gráfica 4

Baldíos adjudicados durante la República Liberal, 1930-1946

(Número y área)

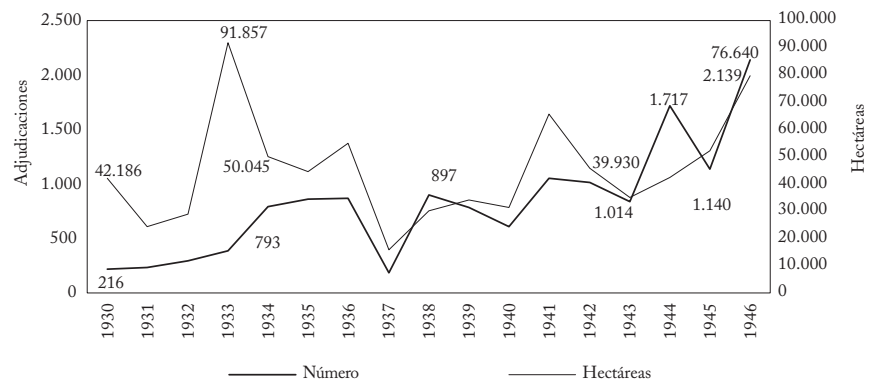

Fuente: Sider-Incoder, elaboración propia.

En la relación entre adjudicación de baldíos y estrategias políticas se pueden considerar dos casos. En el primero, la política se focaliza en los campesinos desterrados que viven y explotan tierras del Estado, como dictan los principios institucionales; de modo la adjudicación de baldíos genera un apoyo de dichos grupos en forma democrática. En el segundo, la adjudicación de grandes extensiones de tierras a un solo beneficiario puede generar un vínculo estrecho con el terrateniente lograr así un apoyo en su zona de influencia.

Desde la Hegemonía Conservadora hay una tensión entre la entrega y titulación de tierras a grandes latifundistas y el acceso de los campesinos a la tierra, la cual se manifiesta en el discurso de cada partido. El partido conservador ha respaldado a los propietarios, así como los linderos y las relaciones laborales existentes en las haciendas; 
el partido liberal se ha mostrado contrario al latifundio con el fin de dar acceso a la tierra a los campesinos o incentivar la agro-industria, (Londoño, 2010). Así, la posible estrategia electoral está articulada al discurso partidista.

Sin embargo, no hay acuerdo sobre cuál de los dos partidos se beneficiaba con la política de adjudicación de baldíos. Según Posada (2000), el campo y el campesinado mantenían un estrecho vínculo con el partido conservador. Green (2013) sostiene que durante la República Liberal la maquinaria liberal logró penetrar en el campo y ganar apoyo para su partido. La estrategia debía entonces atraer a los votantes indecisos y fortalecer la maquinaria liberal mediante el control gamonalista que, como señala Bergquist (1978), permitía repartir recursos a nivel local en beneficio del partido a nivel nacional.

Así, la política de tierras puede estar asociada a la distribución de recursos para obtener apoyo electoral, no solo repartiendo predios a un mayor número de campesinos, sino también a los gamonales, que podían devolver este favor consiguiendo votos. Según Deas (1973), el gamonal no solía ser un gran terrateniente y los grandes latifundios no garantizaban el poder político. Sin embargo, el control de las tierras podía atender las necesidades locales y usarlas para repartir bienes y reclutar seguidores para que votaran por su partido.

\section{CONTEXTO POLÍTICO}

Algunos autores sugieren que el largo bipartidismo refleja lealtades y fidelidades que explicarían el apoyo a los partidos basado en la identidad ideológica (Tirado, 1986; Molina, 1970). Otros autores señalan que, en un ambiente marcado por diferencias ideológicas, los partidos usaron la maquinaria de manera para manipular el sistema electoral ${ }^{6}$, así como la compra de votos y el fraude electoral para ganar elecciones y permanecer en el poder. El clientelismo, una práctica política de ambos partidos, le restó peso al discurso ideológico e influencia entre los nuevos votantes (Ortiz, 1985; Posada, 1997; Dávila y Leal 1998, Green, 2013, y Gutiérrez, 2017) ${ }^{7}$. También se ha afirmado que el fraude y la manipulación de resultados eran más frecuentes en zonas leales al gobierno de turno, dejando cierto margen a los municipios y

${ }^{6}$ El concepto de maquinaria se refiere al uso de influencias y dádivas regionales por parte de los gamonales para influenciar la política local y, a su vez, los resultados electorales nacionales.

7 Se mencionan cinco tipos de fraude: uso de cédulas falsas o múltiples, confiscación de cédulas, obstrucción de un partido para verificar resultados, robo de papeletas o urnas y alteración de los resultados. 
departamentos de la oposición o indecisos. Según Gutiérrez, la derrota del partido conservador en 1930 llevó a que sectores importantes de cada partido se inclinaran a los extremos del espectro político y así se debilitó el centro. De modo que la estrategia pudo virar a los extremos, aunque se intentaba capturar al centro.

Esos planteamientos no descartan las posibles estrategias para captar votantes en el nuevo contexto de interacción social y económica. El hecho de que el fraude ocurriera en zonas leales sugiere otra estrategia en las regiones indecisas. Como señala Palacios, desde los años veinte, "los sectores populares empezaron a ser representados legítimamente, con todos los zigzagueos que se quiera" (1999, p. 290). Paulatinamente se fueron reconociendo las expresiones de sectores económicos y sociales nacientes y la necesidad de incluirlos en el discurso político. Y se adoptaron nuevas estrategias para atraer a los grupos sociales en ascenso.

La República Liberal comenzó con la llegada del partido liberal a la presidencia en 1930, luego de la larga hegemonía conservadora que ejerció el poder desde finales del siglo XIX. En ese año, Enrique Olaya Herrera ganó las elecciones presidenciales con el 44\% los votos, gracias a la división de partido conservador. E1 partido liberal mantuvo la presidencia hasta 1946, cuando el candidato conservador Mariano Opina Pérez ganó las elecciones, también por una división del partido liberal ${ }^{8}$, cuyos dos candidatos obtuvieron más del $60 \%$ de la votación, lo que indica que era la principal fuerza política del país.

Para permanecer en el poder, después de 50 años de poder conservador, el partido liberal tuvo que adoptar una serie de estrategias que lo reportan buenos resultados en las urnas. La adjudicación de baldíos pudo ser una de ellas; es posible entonces que la posibilidad de que la política de tierras no solo respondiera a la ideología liberal sino que fuese utilizada para garantizar un caudal electoral desde 1930 en adelante.

E1 triunfo de Olaya Herrera y el fin de la hegemonía conservadora obedecieron a razones económicas, sociales y políticas, como las tensiones entre sindicalistas y empresarios; los efectos de la Gran Depresión, que redujo notablemente los precios de las exportaciones, y la reducción del crédito internacional; y a la división del partido -entre dos candidatos: Guillermo Valencia y Alfredo Vásquez-, que

${ }^{8}$ En 1946 se presentaron dos candidatos liberales a las elecciones presidenciales: Gabriel Turbay y Jorge Eliécer Gaitán. Ninguno obtuvo los votos suficientes para ganar las elecciones, pero el porcentaje que obtuvieron entre ambos indica un apoyo mayoritario al partido liberal. 
la Iglesia Católica, aliada eterna del partido, no pudo reparar porque no se inclinó a tiempo por ninguno de ellos (Bushnell, 2006).

La República Liberal emprendió grandes cambios en la organización política, social y económica del país, como el papel más intervencionista del Estado en la economía, el inicio de los cambios en la estructura y la actividad agrícola y la mejora del bienestar social, con la ley de tierras y la organización de sindicatos (LeGrand, 1988; Machado, 2009), entre otras medidas

Según la literatura, la presidencia de Olaya Herrera fue un gobierno de transición. El gobierno siguiente, al mando de Alfonso López Pumarejo durante 1934 y 1938, se conoce como la Revolución en Marcha, debido a sus reformas y a los grandes cambios resultantes, que llevaron al orden constitucional y dieron piso jurídico a las nuevas transformaciones que pretendía el gobierno de López (Botero, 2006). Entre sus principales reformas se destaca el sufragio universal masculino, que tuvo grandes efectos en materia electoral, pues incluyó nuevos votantes, en su mayoría campesinos y obreros, sin ingresos ni propiedades, que por vez primera participaban en la contienda política ${ }^{9}$. En este periodo también se reconoció el derecho de huelga, y se legisló la reforma agraria (Ley 200 de 1936).

La República Liberal terminó con el segundo gobierno de López Pumarejo (1942-1946), que tuvo detractores entre los conservadores y los liberales moderados; y, además, enfrentó la crisis económica causada por la Segunda Guerra Mundial. El contexto desfavorable no permitió llevar a cabo los cambios sociales que había prometido, y tuvo que revertir algunos de los más importantes del periodo anterior, como la consolidación del Estado intervencionista y la Ley 200 de 1936, debilitada por la Ley 100 de 1944. López Pumarejo renunció y Alberto Lleras Camargo terminó el periodo presidencial en 1946.

En términos electorales, la República Liberal buscó "liberalizar"los municipios tradicionalmente conservadores, y fortalecer los liberales, en una lucha que incluyó las reformas políticas y sociales, el discurso a obreros y campesinos y la influencia de la prensa (Acevedo y Correa, 2016). Es decir, se esforzó por ampliar el apoyo popular a su ideario para permanecer en el poder. Según Sánchez y Marteens (1983), el crecimiento de los “militantes" aumentó el número de personas que podían participar en la dirección del partido, así como el número de agentes e intermediarios políticos con ambiciones de poder, y la necesidad de retribuirlos, bien fuese en el juego electoral o en la arena

9 Antes solo podían votar hombres mayores de edad, alfabetos, con renta o propiedad. 
política. Según Palacios (1999), los liberales movilizaron al electorado proponiendo nuevos contenidos sociales de participación ciudadana. Esta decisión pudo afectar el alcance de la ejecución de las políticas, incluida la de tierras. Pese a esos esfuerzos, ninguno de los candidatos liberales pudo vencer a Mariano Ospina Pérez, quien triunfó en las elecciones presidenciales de $1946^{10}$ (cuadro 2).

Cuadro 2

Resultados de las elecciones presidenciales de 1930 y 1946

\begin{tabular}{lllc}
\hline Año & \multicolumn{1}{c}{ Candidato } & \multicolumn{1}{c}{ Partido } & Porcentaje de votos \\
\hline 1930 & Enrique Olaya Herrera & Liberal & 44 \\
& Guillermo Valencia Castillo & Conservador & 29 \\
& Alfredo Vásquez Cobo & Conservador & 27 \\
\hline 1946 & Mariano Ospina Pérez & Conservador & 40 \\
& Gabriel Turbay & Liberal & 36 \\
& Jorge Eliécer Gaitán & Liberal & 24 \\
\hline
\end{tabular}

Fuente: Ministerio del Interior, elaboración propia.

\section{ESTRATEGIA EMPÍRICA}

E1 trabajo analiza la relación entre distribución de tierras y resultados electorales en los 16 años en que se consolidó el partido liberal (1930-1946). No solo examina el comportamiento electoral en 1930 y la adjudicación de baldíos, sino la posible relación entre la entrega de tierras y los resultados electorales de 1946.

\section{DATOS}

Se usan datos desagregados a nivel municipal para determina los beneficiarios de la adjudicación de baldíos. La primera fuente de datos es el universo de adjudicación de baldíos del Sistema de Información de Desarrollo Rural (Sider) a cago del Instituto Colombiano de Desarrollo Rural (Incoder) ${ }^{11}$, que incluye el número de predios entregados y las hectáreas adjudicadas por año y municipio entre 1901 y 2017. Aunque el periodo de análisis es 1930-1946, se tienen en cuenta las adjudicaciones anteriores. La segunda fuente es la compilación de los resultados electorales del Ministerio del Interior ${ }^{12}$. Para construir las variables teniendo en cuenta la población y la superficie municipal se tomaron los datos del Dane; además se incluyeron controles geo-

10 E1 candidato liberal popular, Jorge Eliécer Gaitán, generó suspicacias entre las élites del partido, y estas apoyaron a Gabriel Turbay.

11 Actualmente, Agencia Nacional de Tierras

${ }^{12} \mathrm{La}$ información electoral fue potestad del Ministerio del Interior hasta 1958, cuando se creó la Registraduría Nacional del Estado Civil, que entre otras funciones lleva el registro electoral. 
gráficos como la altura del municipio, la superficie apta para cultivos y el nivel de erosión, obtenidos en el Instituto Geográfico Agustín Codazzi. Estos datos forman una base de información novedosa que incluye varias variables que no se habían analizado en conjunto. E1 cuadro 3 muestra las estadísticas descriptivas de las variables usadas en las estimaciones, entre ellas el número de predios adjudicados en el periodo y las adjudicaciones por tamaño de los predios.

Cuadro 3

Estadísticas descriptivas

\begin{tabular}{lccccc}
\hline Variables & Promedio & Desv. est. & Mínimo & Máximo & $\mathrm{N}$ \\
\hline Margen de victoria (1930) & $-8,965$ & 60,110 & -100 & 100 & 684 \\
D. partido liberal (1946) & 0,600 & 0,474 & 0 & 1 & 795 \\
\% partido liberal & 58,138 & 27,655 & 0,097 & 100 & 795 \\
D. Gaitán & 0,244 & 0,427 & 0 & 1 & 795 \\
D. Turbay & 0,399 & 0,474 & 0 & 1 & 795 \\
\hline D. adj. totales & 0,316 & 0,465 & 0 & 1 & 684 \\
Log núm. adj. totales & 0,863 & 1,520 & 0 & 7,003 & 684 \\
Log núm. adj. (<3) & 0,186 & 0,714 & 0 & 6,894 & 684 \\
Log núm. adj. (3-10) & 0,300 & 0,782 & 0 & 5,282 & 684 \\
Log núm. adj. $(10-20)$ & 0,424 & 0,937 & 0 & 5,501 & 684 \\
Log núm. adj. $(20-200)$ & 0,652 & 1,263 & 0 & 6,332 & 684 \\
Log núm. adj. $(>200)$ & 0,179 & 0,516 & 0 & 4,025 & 684 \\
\hline Prop. núm. adj. $(<3) /$ Total & 2,108 & 10,639 & 0 & 100 & 684 \\
Prop. núm. adj. (3-10)/Total & 3,030 & 9,619 & 0 & 100 & 684 \\
Prop. núm. adj. (10-20)/Total & 6,036 & 15,419 & 0 & 100 & 684 \\
Prop. núm. adj. (20-200)/Total & 16,286 & 29,726 & 0 & 100 & 684 \\
Prop. núm. adj. $(>200) /$ Total & 4,119 & 16,062 & 0 & 100 & 684 \\
\hline
\end{tabular}

Fuente: cálculos propios.

Entre 1930 y 1946 se adjudicaron 14.043 predios con una superficie de 768.894 hectáreas. La política de adjudicación de baldíos se centró en unos 300 municipios, en los que ya había una ampliación de la frontera agrícola para cultivar café y banano y criar ganado, aunque también se entregaron tierras para proyectos mineros, consolidar de áreas municipales, proteger áreas naturales (senderos hídricos) y aclarar títulos existentes. Por municipios, se adjudicó un promedio de 50 predios y de unas 56 hectáreas. En cuanto al tamaño de los predios adjudicados, la gráfica 3 muestra que el mayor número tenía de 20 a 200 hectáreas, un 30\% de los predios adjudicados, mientras que solo el 3\% tenía más de 200 hectáreas.

En los municipios de los que se tiene información, el 43,2\% votó por el partido liberal en 1930 y en 1946, al 60,9\%, un aumento que lo convirtió en la fuerza política mayoritaria, aunque perdió en las elecciones de 1946. La variable Margen de victoria (1930) es la diferencia porcentual entre los votos para el partido liberal y los votos 
para el partido conservador. La variable D.partido liberal(1946) indica si el partido liberal obtuvo más votos que el partido conservador en 1946 y Porcentaje partido liberal (1946) es el porcentaje de votos que obtuvo el partido liberal en 1946. Estas variables reflejan el nivel de lealtad de los municipios hacia los partidos políticos.

Usamos los resultados de la votación nacional a la presidencia, a nivel municipal porque en el periodo que analizamos las autoridades intermedia y local eran designadas por el presidente, y no había elecciones de gobernadores ni de alcaldes. Y, además, porque el diseño de la política de tierras se concentraba en el presidente y su implementación en las entidades designadas por el ejecutivo ${ }^{13}$.

\section{Metodología}

Este trabajo analiza empíricamente la posible relación entre la adjudicación de baldíos y los fines electorales. Se pregunta si la adjudicación de baldíos entre 1930 y 1946 se dirigió a los votantes indecisos para cambiar su intención de voto a favor del partido liberal y si los baldíos adjudicados fueron un medio efectivo para aumentar su votación en las elecciones presidenciales de 1946.

Para estimar la asociación entre los municipios qué votaron por el partido liberal y la adjudicación de baldíos se estimó una ecuación de MCO utilizando los datos de la elección presidencial de 1930, la cual compara los municipios donde ganó el partido liberal y aquellos donde ganó el partido conservador, para establecer si hubo alguna diferencia en las adjudicaciones posteriores en estos municipios.

Puesto que la preferencia de los municipios por el partido liberal puede estar correlacionada con ciertas variables socioeconómicas, la comparación de la adjudicación donde ganó uno u otro partido puede no ser acertada ya que la decisión puede ser efecto de características intrínsecas de los municipios. Por ello se incluyó una matriz de controles municipales - población total, nivel de alfabetismo y variables geográficas, entre otras- para corregir por las posibles variables no observables:

Log NumAdju $u_{i, 1930-1946}=\beta_{1}+\beta_{2}$ Margen $_{1930}+\beta_{3}$ Margen $_{1930}+\eta_{4} X_{i, t}+\varepsilon_{i}$

donde Log NumAdju $u_{i, 1930-1946}$ es el número de adjudicaciones (en logaritmos) adjudicadas al municipio en el periodo 1930-1946.

${ }^{13}$ La política de adjudicación de baldíos estaba en manos del presidente y del Ministerio de Agricultura que, solicitaba información municipal sobre la demanda de baldíos y establecía los mecanismos para adjudicarlos. 
Por otra parte, para determinar responder si los baldíos adjudicados fueron un medio efectivo para ganar apoyo en la elección presidencial de $1946^{14}$, se utilizó el siguiente modelo MCO:

PorcentajeLiberal $_{i, 1946}=\beta_{1}+\beta_{2}$ LogNumAdju $_{1930-1945}+\beta_{3}$ Margen $_{1930}+$ $\beta_{3}$ Margen $2_{1930}+\eta_{4} X_{i, t}+\varepsilon_{i}$

donde PorcentajeLiberal ${ }_{i, 1946}$ es una variable dicotómica para tres casos: si en el municipio ganó el partido liberal, si ganó Gabriel Turbay y si ganó Jorge Eliécer Gaitán en 1946; es decir, se hicieron tres estimaciones distintas. LogNumAdju $u_{1930-1945}$ representa las adjudicaciones de todo el periodo (en logaritmo)en cada municipio. Teniendo en cuenta que durante el siglo XX la afiliación partidista de los municipios era muy fuerte, se incluyó la variable Margen $_{1930}$ que indica si el partido liberal ganado en el municipio en 1930 . Por su parte, $X_{i, t}$ recoge los controles sociales y geográficos mencionados.

\section{RESULTADOS}

Con respecto al primer interrogante, la relación entre el partido que ganó en municipio y la política de tierras, se encontraron los resultados que se muestran en el cuadro 4.

La columna (1) presenta los resultados del número de adjudicaciones según el margen de victoria. Por cada punto porcentual que aumenta el margen de victoria en 1930, el número de adjudicaciones totales aumenta en un 0,63\%. Las columnas (2) a (6) muestran los resultados según el tamaño de los predios adjudicados. Los resultados son positivos y significativos para el número de predios de microfundio, minifundio, pequeña propiedad y mediana propiedad. La columna (2) indica que por cada punto porcentual de aumento del margen de victoria en 1930 los microfundios crecen en 0,39. Este efecto positivo se mantiene hasta cuando el margen de victoria es de 18 puntos porcentuales, según la especificación cuadrática. Según la columna (3), el efecto positivo en los minifundios es de 0,54 por cada punto porcentual de aumento del margen de victoria, hasta 27 puntos porcentuales según la especificación cuadrática.

La columna (4) muestra que el efecto positivo de cada punto porcentual de aumento del margen de victoria incrementa en 0,44 puntos la adjudicación de predios pequeños, hasta 29 puntos porcentuales según la especificación cuadrática. Y la columna (5), que el efecto

\footnotetext{
${ }^{14}$ No sobra aclara que si bien el partido liberal tuvo la mayoría de los votos en las elecciones de 1946 (el 60\%), no ganó las elecciones pues ninguno de sus dos candidatos alcanzó la mayoría.
} 
positivo en la mediana propiedad es de 0,57 puntos, hasta 30 puntos porcentuales. En la adjudicación de latifundios no se encuentra una relación significativa, lo que indica que la entrega de grandes extensiones de tierra no estuvo asociada al desempeño de los resultados electorales anteriores.

Cuadro 4

Resultados MCO. Margen de victoria y adjudicación de tierra

\begin{tabular}{|c|c|c|c|c|c|c|}
\hline \multicolumn{7}{|c|}{ Variable dependiente: logaritmo del número de adjudicaciones } \\
\hline & $(1)$ & $(2)$ & (3) & (4) & (5) & (6) \\
\hline & Todas & Micro & Mini & Pequeña & Mediana & Latifundio \\
\hline Margen_1930 & $0,00630^{* *}$ & $0,00392^{* * * *}$ & $0,00540^{* * * *}$ & $0,00439^{* *}$ & $0,00572^{* * *}$ & 0,00058 \\
\hline & $(0,0030)$ & $(0,0013)$ & $(0,0016)$ & $(0,0020)$ & $(0,0026)$ & $(0,0010)$ \\
\hline$\left(\right.$ Margen_1930) ${ }^{2}$ & $-0,00002$ & $-0,00001^{* * *}$ & $-0,00002^{* * * *}$ & $-0,00001^{*}$ & $-0,00002^{*}$ & $-0,00000$ \\
\hline & $(0,0000)$ & $(0,0000)$ & $(0,0000)$ & $(0,0000)$ & $(0,0000)$ & $(0,0000)$ \\
\hline Constante & $1,7842^{*}$ & 0,2834 & $1,0711^{*}$ & $1,3179^{*}$ & $1,7865^{* * *}$ & $-0,1512$ \\
\hline & $(1,0261)$ & $(0,5344)$ & $(0,5884)$ & $(0,6961)$ & $(0,8790)$ & $(0,3523)$ \\
\hline Observaciones & 634 & 634 & 634 & 634 & 634 & 634 \\
\hline $\mathrm{R}^{2}$ ajustado & 0,2342 & 0,179 & 0,1232 & 0,1291 & 0,1809 & 0,1463 \\
\hline Controles & Sí & Sí & Sí & Sí & Sí & Sí \\
\hline
\end{tabular}

Errores estándar entre paréntesis; * $\mathrm{p}<0,1 ;{ }^{* *} \mathrm{p}<0,05 ;{ }^{* * * *} \mathrm{p}<0,01$.

Fuente: elaboración propia.

Los resultados anteriores son consistentes con el propósito del partido liberal de ampliar el acceso a la tierra y sanear la propiedad de los colonos que explotaban la tierra. También coinciden con la tesis de Sánchez y Marteens (1983), para quienes la política de tierras de la República Liberal buscaba consolidar una burguesía agraria de pequeños y medianos propietarios que respondiera con mayor agilidad a las demandas del mercado. Así, la elección presidencial de 1930 guarda relación con la ampliación de los derechos de los campesinos y la creación de pequeños y medianos propietarios capitalistas.

En cuanto a la relación entre las adjudicaciones realizadas en 1930-1946 y los resultados de la elección a la presidencia de 1946, el cuadro 5 muestra los resultados de los modelos de MCO. Puesto que no se encuentra una correlación significativa entre las adjudicaciones y la probabilidad de votar por el partido liberal, la posible estrategia de aumentar el apoyo electoral entregando tierras no fue efectiva para ganar las elecciones en 1946. En cambio, la entrega de microfundios está asociada en forma negativa con el porcentaje de victoria liberal.

Puesto que la historiografía sostiene que una de las principales razones para que el partido no ganara la presidencia fue su fuerte división y la presentación de dos candidatos, se incluyeron dos va- 
riables dicotómicas adicionales; la primera con un valor de 1 si en el municipio ganó Gabriel Turbay y de 0 en caso contrario; y la segunda con valores idénticos donde ganó Jorge Eliécer Gaitán. Los resultados de esta nueva especificación se muestran en los cuadros 6 y 7 .

Cuadro 5

Resultados MCO

Porcentaje de victoria liberal en 1946 y adjudicaciones previas

\begin{tabular}{|c|c|c|c|c|c|c|}
\hline \multicolumn{7}{|c|}{ Variable dependiente: Porcentaje de victoria liberal (1946) } \\
\hline & $(1)$ & (2) & (3) & (4) & (5) & (6) \\
\hline Variables & Todas & Micro & Mini & Pequeña & Mediana & Latifundio \\
\hline Adjudicaciones & $-0,458$ & $-1,291^{*}$ & -1,009 & $-0,267$ & $-0,421$ & $-1,449$ \\
\hline & $(0,544)$ & $(0,782)$ & $(0,822)$ & $(0,813)$ & $(0,666)$ & $(1,213)$ \\
\hline Margen_1930 & $\begin{array}{c}0,567^{* * * *} \\
(0,058)\end{array}$ & $\begin{array}{c}0,570^{\text {****** }} \\
(0,058)\end{array}$ & $0,570^{* * * * *}$ & $0,566^{* * *}$ & $0,567^{* * * * *}$ & $0,566^{\text {****** }}$ \\
\hline$(\text { Margen_1930) })^{2}$ & $\begin{array}{c}-0,00001^{\text {****** }} \\
(0,0000)\end{array}$ & $\begin{array}{c}-0,00001^{* * * *} \\
(0,0000)\end{array}$ & $\begin{array}{c}-0,00001^{* * * * *} \\
(0,0000)\end{array}$ & $\begin{array}{c}-0,00001^{* * * * *} \\
(0,0000)\end{array}$ & $\begin{array}{c}-0,00001^{* * * *} \\
(0,0000)\end{array}$ & $\begin{array}{c}-0,00001^{* * * * *} \\
(0,0000)\end{array}$ \\
\hline Constante & $\begin{array}{c}106,347^{* * * *} \\
(12,877)\end{array}$ & $\begin{array}{c}106,004^{\text {****** }} \\
(12,589)\end{array}$ & $\begin{array}{c}106,659^{* * * *} \\
(12,850)\end{array}$ & $\begin{array}{c}105,893^{* * * *} \\
(12,963)\end{array}$ & $\begin{array}{c}106,265^{\text {***** }} \\
(12,963)\end{array}$ & $\begin{array}{c}105,348^{* * * *} \\
(12,626)\end{array}$ \\
\hline Observaciones & 617 & 617 & 617 & 617 & 617 & 617 \\
\hline $\mathrm{R}^{2}$ ajustado & 0,548 & 0,548 & 0,548 & 0,547 & 0,548 & 0,548 \\
\hline Controles & Sí & Sí & Sí & Sí & Sí & Sí \\
\hline
\end{tabular}

Errores estándar en paréntesis; ${ }^{*} \mathrm{p}<0,1 ;{ }^{* *} \mathrm{p}<0,05 ;{ }^{* * *} \mathrm{p}<0,01$.

Fuente: elaboración propia.

La entrega de tierras baldía durante la República Liberal está correlaciona positivamente con la probabilidad de que Gaitán ganara en el municipio, como muestran las columnas (2) y (3) del cuadro 6. Un aumento del $1 \%$ en el número de microfundios adjudicados aumenta en un 3\% el porcentaje de votos por Gaitán, y un aumento del $1 \%$ en el número de minifundios adjudicados aumenta en un $2 \%$ eses porcentaje. Estos resultados son corroborados por el comportamiento del porcentaje de votos por Turbay, que tiene una asociación negativa con la de microfundios y minifundios (columnas (2) y (3) del cuadro 7). Además, el signo negativo de todos los tamaños de predio es consistente con la idea por más esfuerzos que hubiera hecho el partido liberal para acercar el campo a sus intereses era leal al partido conservador. Este resultado puede reflejar el hecho de que el discurso que Gaitán era atractivo para los trabajadores urbanos y rurales que comenzaban a empoderarse. En zonas rurales marcadamente conservadoras, el discurso gaitanista pudo tener mayor eco entre quienes empezaban a tener vínculos directos con la tierra después de romper las relaciones de dependencia con los hacendados.

Los resultados mencionados concuerdan con los trabajos que señalan que los campesinos y la élite terrateniente eran de filiación 
conservadora (Posada, 2007), lo cual quizá explicar que la vertiente liberal moderada no captó votos asociado con la adjudicación de baldíos; así como con los que argumentan que considera que la propuesta gaitanista de ampliar la democracia obtuvo votos de nuevos electores, sobre todo de pequeños propietarios (Bushnell, 2006).

Cuadro 6

Votos por Gaitán en 1946 y adjudicaciones en 1930-1945

\begin{tabular}{|c|c|c|c|c|c|c|}
\hline \multicolumn{7}{|c|}{ e de votos por J.E. Gaitán } \\
\hline & $(1)$ & $(2)$ & (3) & (4) & $(5)$ & $(6)$ \\
\hline & Todas & Micro & Mini & Pequeña & Mediana & Latifundio \\
\hline Adjudicaciones & $-0,949$ & $2,803^{* *}$ & $2,418^{* *}$ & $1,734^{*}$ & 0,682 & 0,352 \\
\hline & $(0,650)$ & $(1,240)$ & $(1,064)$ & $(0,965)$ & $(0,777)$ & $(1,644)$ \\
\hline Margen_1930 & $0,148^{* * * *}$ & $0,143^{* * * *}$ & $0,141^{* * * *}$ & $0,146^{* * * *}$ & $0,150^{* * * *}$ & $0,153^{* * *}$ \\
\hline & $(0,051)$ & $(0,051)$ & $(0,051)$ & $(0,051)$ & $(0,051)$ & $(0,051)$ \\
\hline (Margen_1930) ${ }^{2}$ & 0 & 0 & 0 & 0 & 0 & 0 \\
\hline & $(0,0000)$ & $(0,0000)$ & $(0,0000)$ & $(0,0000)$ & $(0,0000)$ & $(0,0000)$ \\
\hline Constante & $\begin{array}{c}31,736^{\text {**** }} \\
(15,832)\end{array}$ & $\begin{array}{c}32,401^{* * * *} \\
(15,702)\end{array}$ & $\begin{array}{c}30,721^{\text {***** }} \\
(15,824)\end{array}$ & $\begin{array}{c}31,028^{* * * *} \\
(15,885)\end{array}$ & $\begin{array}{c}32,244^{* * * *} \\
(15,839)\end{array}$ & $\begin{array}{c}33,492^{\text {****}} \\
(15,707)\end{array}$ \\
\hline Observaciones & 617 & 617 & 617 & 617 & 617 & 617 \\
\hline $\mathrm{R}^{2}$ ajustado & 0,315 & 0,318 & 0,318 & 0,316 & 0,313 & 0,312 \\
\hline Controles & Sí & Sí & Sí & Sí & Sí & Sí \\
\hline
\end{tabular}

Errores estándar en paréntesis; ${ }^{*} \mathrm{p}<0,1 ;{ }^{* *} \mathrm{p}<0,05 ;{ }^{* * * *} \mathrm{p}<0,01$.

Fuente: elaboración propia.

Cuadro 7

Votos por Turbay en 1946 y adjudicaciones en 1930-1945

Variable dependiente: Porcentaje de votos por G. Turbay en 1946

\begin{tabular}{|c|c|c|c|c|c|c|}
\hline & $\begin{array}{c}(1) \\
\text { Todas }\end{array}$ & $\begin{array}{c}(2) \\
\text { Micro }\end{array}$ & $\begin{array}{l}\text { (3) } \\
\text { Mini }\end{array}$ & $\begin{array}{c}\text { (4) } \\
\text { Pequeña }\end{array}$ & $\begin{array}{c}\text { (5) } \\
\text { Mediana }\end{array}$ & $\begin{array}{c}\text { (6) } \\
\text { Latifundio }\end{array}$ \\
\hline Adjudicaciones & $\begin{array}{l}-1,406^{*} \\
(0,752)\end{array}$ & $\begin{array}{c}-4,095^{\text {***** }} \\
(1,188)\end{array}$ & $\begin{array}{c}-3,427^{* * * *} \\
(1,152)\end{array}$ & $\begin{array}{l}-2,001^{*} \\
(1,113)\end{array}$ & $\begin{array}{l}-1,103 \\
(0,923)\end{array}$ & $\begin{array}{l}-1,802 \\
(1,793)\end{array}$ \\
\hline Margen_1930 & $\begin{array}{c}0,419^{* * * *} \\
(0,069)\end{array}$ & $\begin{array}{c}0,427^{* * * *} \\
(0,067)\end{array}$ & $\begin{array}{c}0,429^{* * * *} \\
(0,069)\end{array}$ & $\begin{array}{c}0,420^{* * * *} \\
(0,069)\end{array}$ & $\begin{array}{c}0,417^{* * * *} \\
(0,069)\end{array}$ & $\begin{array}{l}0,412^{* * * *} \\
(0,068)\end{array}$ \\
\hline$\left(\right.$ Margen_1930) ${ }^{2}$ & $\begin{array}{l}-0,001^{\text {***** }} \\
(0,0000)\end{array}$ & $\begin{array}{l}-0,001^{\text {***** }} \\
(0,0000)\end{array}$ & $\begin{array}{l}-0,001^{\text {***** }} \\
(0,0000)\end{array}$ & $\begin{array}{l}-0,001^{\text {***** }} \\
(0,0000)\end{array}$ & $\begin{array}{l}-0,001^{\text {***** }} \\
(0,0000)\end{array}$ & $\begin{array}{l}-0,001^{* * * *} \\
(0,0000)\end{array}$ \\
\hline Constante & $\begin{array}{c}74,611^{* * * *} \\
(18,477)\end{array}$ & $\begin{array}{c}73,602^{* * * *} \\
(18,105)\end{array}$ & $\begin{array}{c}75,938^{* * * *} \\
(18,396)\end{array}$ & $\begin{array}{c}74,865^{* * * *} \\
(18,519)\end{array}$ & $\begin{array}{c}74,021^{* * * *} \\
(18,573)\end{array}$ & $\begin{array}{c}71,856^{* * * *} \\
(18,205)\end{array}$ \\
\hline $\begin{array}{l}\text { Observaciones } \\
\mathrm{R}^{2} \text { ajustado } \\
\text { Controles }\end{array}$ & $\begin{array}{c}617 \\
0,197 \\
\text { Sí } \\
\end{array}$ & $\begin{array}{c}617 \\
0,201 \\
\text { Sí } \\
\end{array}$ & $\begin{array}{c}617 \\
0,201 \\
\text { Sí } \\
\end{array}$ & $\begin{array}{c}617 \\
0,196 \\
\text { Sí } \\
\end{array}$ & $\begin{array}{c}617 \\
0,194 \\
\text { Sí } \\
\end{array}$ & $\begin{array}{c}617 \\
0,193 \\
\text { Sí } \\
\end{array}$ \\
\hline
\end{tabular}

Errores estándar en paréntesis; * $\mathrm{p}<0,1 ;{ }^{* *} \mathrm{p}<0,05 ;{ }^{* * * *} \mathrm{p}<0,01$.

Fuente: elaboración propia.

No obstante, la principal beneficiaria de la política de tierras fue la clase media. Jorge Eliécer Gaitán estuvo a favor de la Ley 200 de 1936 en sus inicios y personificó la idea de redistribuir la riqueza y la tierra, y era de esperar que las personas de clase media y baja apoyaran las ideas gaitanistas. En cambio, Gabriel Turbay defendía los intereses de 
la clase dirigente, contraria al ideario socialista de Gaitán (Bushnell, 2006); por ello recibió menos votos de la clase media, y las demás clases le mostraron indiferencia.

\section{CONCLUSIONES}

La política colombiana de tierras se puede asociar a los intereses electorales de los dos partidos históricos. En los años treinta, los liberales favorecieron a los votantes leales, otorgándoles más baldíos, y a los electores indecisos, aumentando las adjudicaciones en los municipios donde vencieron a los conservadores por un estrecho margen. Un comportamiento que concuerda con las tesis de Albertus y de Dixit y Londregan que se describen en la revisión bibliográfica.

Nuestros resultados muestran otra faceta de la política de entrega de tierras o baldíos y sus efectos en las elecciones de 1946. En los municipios donde el partido liberal ganó por un alto margen adjudicó un mayor número de predios de todo tamaño, exceptuando latifundios. Pero la estrategia no logró los objetivos que plantea la teoría: ganar elecciones. En los municipios donde hubo mayor adjudicación de baldíos no hay una correlación con la probabilidad de que los liberales lograran una victoria electoral. No obstante, en los municipios que adjudicaron más predios pequeños y medianos, se encuentra una correlación positiva con la probabilidad de votar por el candidato popular. Así, la estrategia de adjudicar baldíos para ganar elecciones le sirvió al candidato inclinado al socialismo, pero fue insuficiente para que el partido liberal ganara en las urnas.

Por último, nuestros resultados complementan los de otros trabajos de carácter cualitativo y abren la puerta a otros estudios que examinen los efectos de la adjudicación de baldíos en el crecimiento económico.

\section{REFERENCIAS BIBLIOGRÁFICAS}

Acevedo, Á. y Correa, J. (2016). Tinta Roja. Prensa, politica y educación en la república liberal (1930-1946). Bucaramanga: Universidad Industrial de Santander.

Albertus, M. (2015). The role of subnational politicians in distributive politics: Political bias in Venezuela's land reform under Chávez. Comparative Political Studies, 48(13), 1667-1710.

Albertus, M., Díaz, A. et al. (2016). Authoritarian survival and poverty traps: Land reform in Mexico. World Development, 77(C), 154-170.

Arango, M. (2014). La tierra en la historia de Colombia. Bogotá: Ediciones Aurora. 
Baland, J. M. y Robinson, J. A. (2008). Land and power: theory and evidence from Chile. American Economic Review, 98(5), 1737-1765.

Banfield, E y Wilson, J. (1963). City politics. Nueva York: Random House.

Bardhan, P. y Mookherjee, D. (2010). Determinants of redistributive politics: An empirical analysis of land reforms in West Bengal, India. American Economic Review, 100(4),1572-1600.

Berry, A. (2002). Valoración de políticas de apoyo a la pequeña empresa: primera aproximación a una metodología regional. Washington: BID.

Botero, S. (2006). La reforma constitucional de 1936, el Estado y las políticas sociales en Colombia. Anuario Colombiano de Historia Social $y$ de la Cultura, 33, 85-109.

Bushnell, D. (2006). Colombia, una nación a pesar de sí misma: de los tiempos precolombinos a nuestros días. Bogotá: Planeta.

Deas, M. (1973). Algunas notas sobre la historia del caciquismo en Colombia. Revista de Occidente, 127, 118-140

Dixit, A. (1996). Special-interest lobbying and endogenous commodity taxation. Eastern Economic Journal, 22(4), 375-388.

Dixit, A., Grossman, G. M. et al. (1997). Common agency and coordination: General theory and application to government policy ma-king. Journal of political economy, 105(4), 752-769.

Dixit, A. y Londregan, J. (1996). The determinants of success of special interests in redistributive politics. Journal of Politics, 58(4), 1132-1155.

Downs, A. (1957). An economic theory of democracy. Nueva York: Harper Collins.

Faguet, J. P., Sánchez, F y Villaveces, J. (2016). The paradox of land reform, inequality and local development in Colombia. London School of Economics and Political Science working paper.

Fajardo, D. (2014). Estudio sobre los orígenes del conflicto social armado, razones de su persistencia y sus efectos más profundos en la sociedad colombiana. Comisión Histórica del conflicto y sus víctimas, [http:// www.centrodememoriahistorica.gov.co/descargas/comisionPaz2015/ FajardoDario.pdf].

Fergusson, L., Larreguy, H. et al. (2015). Political constraints and state capacity: Evidence from a land allocation program in Mexico. LACE working paper 0011.

Formisano, R. P. (1971). The birth of mass political parties. Princeton: Princeton University Press.

Franco-C, A. M., de los Ríos-C., D. et al. (2011). Reforma agraria en Colombia: evolución histórica del concepto hacia un enfoque integral actual. Cuadernos de desarrollo rural, 8(67), 93-119.

Franzese, R. (2002). Electoral and partisan cycles in economic policies and outcomes. Annual Review of Political Science, 5, 365-421

Gelman, A. y Imbens, G. (2014). Why high-order polynomials should not be used in regression discontinuity designs. NBER working paper 20405.

Green, W. J. (2013). Gaitanismo, liberalismo de izquierda y movilización popular. Medellin: Universidad EAFIT

Grossman, G. y Helpman, E. (1992). Protection for sale. Technical report, Cambridge, Mass.; NBER. 
Gutiérrez, F. (2017). La destrucción de una República. Bogotá: Universidad Externado de Colombia y Taurus.

Heshusius, K. (2005). Medición del impacto de un programa de reforma agraria en Colombia. Technical report, Bogotá: Universidad de Los Andes.

Kalmanovitz, S. (2006, 9 de diciembre, párr. 2). El Impuesto Predial. E1 Espectador.

LeGrand, C. (1988). Colonización y protesta campesina en Colombia (18501950). Bogotá: Universidad Nacional de Colombia.

Lindbeck, A. y Weibull, J. W. (1987). Balanced-budget redistribution as the outcome of political competition. Public choice, 52(3), 273-297.

Londoño, R. (2010). Juan de la Cruz Varela. Sociedad y politica en la región del Sumapaz (1902-1984). Bogotá: Universidad Nacional de Colombia.

Machado, A. (2009). Ensayos para la historia de la politica de tierras en Colombia. De la Colonia a la creación del Frente Nacional. Bogotá: Editorial Gente Nueva.

Martínez, O. F. (2013). Colombia, el paradigma de la transformación política de 1930 a 1946. La política inconclusa de "la revolución en marcha" en la República Liberal. Revista Colombiana de Ciencias Sociales, 4(2), 336-347.

Molina, G. (1970). Las ideas liberales en Colombia: 1849-1914. Bogotá: Universidad Nacional de Colombia

Muñoz-M., J. C. et al. (2010). Los caminos del café: Aproximación a la relación entre el conflicto armado rural y la producción cafetera colombiana. Ensayos sobre Política Económica, 28(63), 14-65.

Nazareno, M., Stokes, S. y Brusco, V. (2006). Réditos y peligros electorales del gasto público en la Argentina. Desarrollo Económico, 46(181), 63-88.

Nichter, S (2008) Vote buying or turnout buying? Machine politics and the secret ballot. American Political Science Review, 102(1), 19-31.

Palacios, M. (2011). ¿De quién es la tierra?: propiedad, politización y protesta campesina en la década de 1930. Bogotá: Universidad de los Andes, Fondo de Cultura Económica.

Pécaut, D. (2001). Orden y violencia: evolución socio-politica de Colombia entre 1930 y 1953. Bogotá: Editorial Norma.

Posada C., E. (2000). Las elecciones presidenciales de Colombia en 1930. Revista de Estudios Sociales, 7, 35-47

Robinson, J. A. (2007). ¿Un típico país latinoamericano? Una perspectiva sobre el desarrollo. En J. A. Robinson y M. Urrutia (eds.), Economía colombiana del siglo XX: un análisis cuantitativo (pp. 639-673). Bogotá: Fondo de Cultura Económica

Sánchez, G. G. y Meertens, D. (1983). Bandoleros, gamonales y campesinos. El caso de la Violencia en Colombia. Bogotá: El Áncora.

Scott, J. C. (1972). Patron-client politics and political change in Southeast Asia. American Political Science Review, 66, 91-113

Tirado M., A. (1986). La economía y lo social en la reforma constitucional de 1936. Lecturas de Economía, 21, 81-98. 
Uprimny, R. (1989). Legitimidad, clientelismo y política en Colombia. un ensayo de interpretación. Cuadernos de economía, 10(13), 113-164. Vanegas, I. (2015). Eduardo Santos y las sinsalidas de la República Liberal. Historia y Memoria, 11, 241-270

Villaveces, J. y Sánchez, F. (2014). Tendencias históricas y regionales de la adjudicación de baldíos en Colombia 1900-2012. Documento CEDE, 20, Facultad de Economía, Universidad de los Andes.

Wang, C.-S. y Kurzman, C. (2007). Dilemmas of electoral clientelism: Taiwan, 1993. International Political Science Review, 28(2), 225-245. 